\title{
Erratum to: Effect of calcium chloride on the biocontrol efficacy of two antagonistic yeasts against Penicillium expansum on apple fruit
}

\author{
Jalal Gholamnejad • Hasan Reza Etebarian
}

Published online: 23 October 2009

(C) Springer Science + Business Media B.V. 2009

Erratum to: Phytoparasitica (2009) 37: 255-261

DOI 10.1007/s12600-009-0033-8

The authors of the above mentioned article had submitted the paper as an original research article and stated that it had not been submitted or published elsewhere.

Subsequent to its publication, the Editors discovered that the article in Phytoparasitica included many identical paragraphs and almost identical data presentation structure as those reported in the paper published seven years previously by Tian S.P., Fan Q., Xu Y. \& Jiang A.L in Plant Pathology 51: 352-358, 2002.

The authors were notified of our finding about their fraudulent presentation of other's scientific research and given an opportunity to provide an explanation, but no response was received from them. We regret this lapse of scientific integrity and assure our readers that every effort will be made to avoid such an occurrence in the future.

The online version of the original article can be found at http:// dx.doi.org/10.1007/s12600-009-0033-8.

J. Gholamnejad $(\bowtie) \cdot$ H. R. Etebarian

Department of Plant Protection, University of Tehran,

Abooreihan Campus,

Tehran, Iran

e-mail: jalalgholamnejad2006@gmail.com 